\title{
Nuevos mecanismos participativos: un concepto, distintas realidades
}

\author{
New articipatory policymaking processes: a single concept, \\ different realities
}

No podemos entender quiénes somos sin entender de dónde venimos. Ocurre con las personas pero también con las políticas locales de participación ciudadana. Por ello, el objetivo de esta breve reflexión será doble. En primer lugar, argumentaremos que las nuevas políticas de participación desarrolladas por los ayuntamientos españoles elegidos en las elecciones municipales de 2015 se han movido por sendas considerablemente diversas. En segundo lugar, sugeriremos que estos caminos diferentes tienen que ver con las coaliciones sociopolíticas dominantes en cada uno de los casos y en la interpretación que cada uno de los socios de las mismas realiza sobre cuáles fueron los aciertos y los errores de prácticas participativas previas (Navarro, 1999).

Realizaremos ese recorrido utilizando principalmente tres casos: los de los ayuntamientos de Barcelona, Córdoba y Madrid. Aunque estos representan cierta diversidad de trayectorias, de socios y de resultados, no necesariamente representan correctamente el conjunto de la diversidad de los ayuntamientos donde se produce un cambio político en 2015. Todas las propuestas que se avanzan en este trabajo son más hipótesis y sugerencias a discutir que el resultado de un análisis pormenorizado de las prácticas participativas de estos municipios - un ejercicio, este último, pendiente de realizar de forma sistemática.

Nuestra hipótesis central es que, aunque en todos los casos hubiera cierta voluntad programática de profundizar las herramientas participativas del municipio heredadas de los anteriores gobiernos de derechas, en esos tres ayuntamientos se están desarrollando modelos de participación muy diferentes. Provisionalmente podríamos llamarlos el modelo de la 
proximidad (Barcelona), del diálogo (Córdoba) y de la innovación (Madrid). Antes de pasar a describirlos y a tratar de explicar esas diferentes opciones realizaremos un breve repaso de los antecedentes, enmarcando la trayectoria de esos municipios en la del conjunto de las prácticas participativas de los municipios españoles.

\section{DE AQUELLOS POLVOS...}

Las primeras elecciones municipales democráticas en 1979 podrían presentar alguna similitud aparente con el año 2015 en cuanto a la llegada de nuevas élites políticas locales a los gobiernos de muchos de los ayuntamientos medianos y grandes del país. En ambos momentos, las nuevas candidaturas parecían otorgar un protagonismo considerable a la participación ciudadana. Pero las realidades que unos y otros se encontraron en los municipios fue muy diferente: en el año 1979 había unos déficits brutales de todo tipo de servicios públicos básicos y de infraestructuras urbanísticas y los esfuerzos y resultados principales de aquellas candidaturas se centraron en ese terreno. Solo en algunas ciudades la participación logró hacerse un hueco entre tantas otras prioridades, poniéndose las primeras piedras en forma de mecanismos de participación ciudadana, muy centrados en esos momentos en dar voz a los colectivos sociales organizados.

Aunque cada ciudad tuviera su propio recorrido, la participación ciudadana no vuelve a entrar en la agenda política local de forma generalizada hasta la segunda mitad de los años 90. La nueva oleada de procesos de profundización democrática local seguirá siendo muy diversa en sus ritmos y caminos, aunque la gran mayoría de municipios compartirán al menos un elemento en común: en sociedades cada vez más individualistas, con menos cultura militante tradicional pero con una ciudadanía que reclamaba posibilidades de hacer escuchar su voz de forma individual, muchos ayuntamientos tratarán de crear instrumentos que permitan esta vía, complementando el papel de la sociedad civil organizada. En unas ciudades será a través de presupuestos participativos donde la máxima «una persona, un voto" sea el centro de la apuesta; en otras, ensayando fórmulas de selección aleatoria de los participantes o redactando nuevos reglamentos de participación más abiertos a esas voces.

Estas nuevas fórmulas tendrán sus bondades y sus problemas: se escucharán voces más diversas en la vida política municipal, pero en algunos casos estas voces tendrán menos continuidad y espíritu crítico que las de 
los colectivos organizados. A su vez, estos se sentirán a menudo incómodos en el nuevo escenario y lo acogerán con reticencia, cuando no con abierta oposición. El saldo final y el sabor que cada una de estas experiencias dejará será muy distinto. Con posterioridad, casi todas las grandes ciudades vivirán una travesía del desierto participativo: un período en que los efectos de la crisis y las mayorías absolutas generalizadas de la derecha darán al traste con muchos procesos participativos. Pero la lectura de los éxitos y fracasos de ese período anterior condicionará claramente cómo se afronten las nuevas experiencias que se desarrollarán a partir de 2015.

\section{2. ...ESTOS LODOS}

Después de la irrupción del movimiento $15 \mathrm{M}$ y del protagonismo que el mismo asignó a la participación, esta va a recuperar su protagonismo en la agenda política local. La victoria de muchas candidaturas que se reclamaban herederas de ese espíritu en grandes ciudades y el cambio político que se da en muchas de ellas supondrá un nuevo empuje para el discurso y las prácticas participativas. Nuestra sensación, sin embargo, es que el cuánto y el cómo se incorporaron estas apuestas en las nuevas municipalidades ha sido extremadamente diverso y ha tenido que ver con dos grandes factores: la composición de cada una de las nuevas coaliciones sociopolíticas gobernantes y la lectura que los principales socios de las mismas han hecho de la trayectoria participativa del municipio - su lectura de cuánto, cómo y por qué algunas ideas pueden volver a ser ensayadas o de cuáles deben ser las fuentes de inspiración donde los procesos participativos deben beber.

Córdoba permite ilustrar este argumento con mucha claridad. Por un lado, la intensidad del cambio político es menor: el ejecutivo monocolor del pp es sustituido por un gobierno de coalición PSOE-IU, liderado por la primera fuerza, que cuenta con apoyo externo de Ganemos. Pero si su apuesta participativa parece menos transformadora (ausencia de propuestas participativas innovadoras muy visibles), no es seguramente tanto por las siglas concretas que ocupan cada lugar sino por el diagnóstico que los actores sociopolíticos clave de la ciudad hacen sobre las experiencias del pasado. Así, la iu local recuerda con sabor agridulce el período en que fue una referencia nacional e internacional por los presupuestos participativos que se desarrollaron en la ciudad: estos le costaron enfrentamientos significativos con organizaciones sociales cercanas (Ganuza y Alvarez, 2003). Aunque la apuesta por los mismos pareció mantenerse en un primer mo- 
mento, su desarrollo se congeló ante la falta de apoyo de las principales organizaciones sociales de la ciudad. Otras políticas interesantes desarrolladas desde el departamento de participación liderado por IU, como la Escuela de Participación, otorga mucho menos poder decisivo a la ciudadanía, pero permite engrasar mucho mejor las redes clientelares y las necesidades de los principales aliados sociales de la organización.

También el psoe tenía una versión ambigua sobre el pasado, dado que se habían mostrado muy críticos con los presupuestos participativos desarrollados en su día por IU. Algo faltos de ideas innovadoras y conscientes de la fragilidad de su mayoría social y política, la apuesta de la alcaldesa Isabel Ambrosio ha sido mucho menos la de los procesos innovadores que la de la creación de abundantes espacios (más o menos formalizados) de diálogo político en los que ha incorporado hábilmente a socios externos al gobierno, facilitando así su voz en el proceso político y evitando conflictos posteriores. Un Ganemos muy dividido ha tenido poca capacidad de obligar a los partidos gobernantes a ir mucho más allá de este estilo dialogante de gobierno.

La historia es muy distinta en el caso de Madrid, la ciudad que posiblemente ha hecho la apuesta más rompedora en cuanto a sus políticas de participación. En este caso, el equipo de concejales electos de Ahora Madrid, que gobierna en solitario (aunque con el apoyo externo del PSOE) es posiblemente el más quincemayista de los tres conjuntos de concejales. Aunque otros departamentos desarrollarán también iniciativas participativas, el liderazgo muy claro de las mismas va a corresponder al equipo que lidera Pablo Soto en el departamento de participación. Los actores clave, en este caso, rompen con el incrementalismo propio de casi todas las políticas públicas y empiezan con el contador a cero, como si no hubiera nada que aprender de lo que había hecho ese ayuntamiento, pero sí mucho que aprender de lo que había ocurrido en el movimiento 15M, en Podemos o en espacios de innovación social (con apoyo municipal) como Medialab. En muy poco tiempo se ponen en marcha mecanismos para que la ciudadanía realice propuestas que podrán convertirse en vinculantes, presupuestos participativos a nivel de ciudad y de distrito, consultas ciudadanas con formato referéndum y efectos políticamente vinculantes (Welp, 2017). Todos ellos parten del pequeño decálogo implícito de la vanguardia participativa de esos años: fuerte confianza en la ciudadanía, a la que se otorga capacidad de decisión, voto individual y pequeños intentos de que el proceso pueda tener algún debate, aunque el acento se pone más en el voto y en el uso intensivo de las herramientas on line que en la deliberación. 
Barcelona representa aún un tercer modelo. El principal actor político gobernante es también nuevo (Barcelona en Comú), pero, a diferencia de Madrid, este incorpora a uno de los partidos que ha gobernado muchos años en Barcelona (ICV- EUiA) y el principal responsable técnico del departamento es alguien que ya había ocupado responsabilidades similares con el gobierno tripartito catalán. Este es uno de los factores que posiblemente lleva a una postura que tiende menos a la ruptura total con el pasado y más a la mejora y profundización de lo ya existente. Así, aunque a medio plazo se pondrán en marcha también una considerable batería de herramientas más ambiciosas (desde presupuestos participativos hasta consultas vinculantes), la primera prioridad del nuevo consistorio en este ámbito pasará por profundizar espacios ya ensayados como la participación en el Plan de Acción Municipal y, principalmente, en revitalizar los espacios de consulta y diálogo de proximidad basados en los barrios.

En definitiva, los tres ayuntamientos en los que hemos puesto nuestra mirada representan tres caminos distintos para avanzar y dar forma a políticas participativas. Cada una de ellas puede tener sus méritos y sus limitaciones, pero aquí nos hemos centrado más en entender su elección. Así, esos caminos distintos no responden a decisiones azarosas, sino a la importancia y el protagonismo que tienen distintos actores en las coaliciones sociopolíticas dominantes en cada caso y en las valoraciones que estas hacen de su pasado, de cuáles son las experiencias del mismo de las que aprender o los traumas que no se quieren volver a vivir.

\section{REFERENCIAS BIBLIOGRÁFICAS}

Ganuza, E. y Alvárez de Sotomayor, C. (eds.) (2003): Democracia y presupuestos participativos, Barcelona, Icaria.

Navarro Yáñez, C. J. (1999): El sesgo participativo: innovación democrática en municipios del Sur de Europa (1960-1995), Madrid, csic-Politeya.

Welp, Y. (2017): «Consulta a la Madrileña», Swiss Info. Tomado de: https:// www.swissinfo.ch/democraciadirecta/punto-de-vista_consulta-populara-la-madrileña/43034642 